\title{
Modeling Individualized Sustainable Last Mile Logistics
}

\author{
Markus Trapp (D), Sandra Luttermann (D), Daniel Rippel (D), \\ Herbert Kotzab (D, and Michael Freitag (D)
}

\begin{abstract}
The online grocery trade has received an additional boost from the Covid pandemic. The delivery of such purchases places particular demands on last mile logistics since consumers demand more and more individualized delivery options, e.g., regarding the delivery arrival or the type of transport. At the same time, many consumers are becoming more environmentally conscious, so there is a need to examine further how this particular consumer behavior affects the sustainability of deliveries. This paper develops and presents a simulation model, which considers grocery delivery under different framework conditions. The examined scenarios show that a change in consumer behavior directly impacts last mile logistics systems, mainly by increasing the total number of orders and a slight reduction in emissions through improved vehicle utilization. Nevertheless, the results show that without sufficiently high utilization of delivery vehicles, shopping trips by private car may cause fewer emissions.
\end{abstract}

\footnotetext{
M. Trapp $(\bowtie) \cdot$ D. Rippel

BIBA - Bremer Institut für Produktion und Logistik GmbH, University of Bremen, Bremen, Germany

e-mail: tap@biba.uni-bremen.de; rip@biba.uni-bremen.de

S. Luttermann $\cdot$ H. Kotzab

Faculty of Business Studies and Economics, University of Bremen, Bremen, Germany

e-mail: sandra.luttermann@uni-bremen.de; kotzab@uni-bremen.de

M. Freitag

BIBA - Bremer Institut für Produktion und Logistik GmbH, University of Bremen, Bremen, Germany

Faculty of Production Engineering, University of Bremen, Bremen, Germany

e-mail: fre@biba.uni-bremen.de
} 


\section{Introduction}

Nowadays, more and more consumers are using e-commerce for their purchases, which leads to increased delivery volumes, especially in urban areas. Thereby, we observe that individual order frequencies trigger large numbers of individual shipments of single orders with single packages. Consequently, the utilization of transport means decreases (Pronello et al. 2017; Schnedlitz et al. 2013). From a consumer's point of view, there is also a rising desire for more individuality in the delivery of online ordered goods (Witten and Schmidt 2019). Consumers expect flexible deliveries as well as delivery services that are individually tailored to their lifestyles. This refers particularly to timely delivery of ordered goods, direct deliveries to the front door, and well-determined delivery dates (Wegner 2019). At the same time, it is apparent that the probability of personal receipt and thus successful delivery tends to decline.

Furthermore, consumers are becoming more environmentally aware and want to purchase in an environmentally sustainable manner (Ternès et al. 2015). However, this conflicts with increasing traffic volumes that are generated by e-commerce. Thereby, the so-called last mile often turns out to be inefficient, costly, and environmentally damaging (Gevaers et al. 2011). Especially urban delivery areas are challenged by more traffic congestions, air and noise pollution, traffic accidents, and greenhouse gas emissions. These new complex logistics structures put retailers as well as logistics service providers under great cost pressure (Savelsbergh and Van Woensel 2016). Accordingly, alternative concepts for the last mile need to be developed for the future, which are both, sustainable as well as individual.

This paper examines different delivery options for online grocery retailing that allow for individual adjustments of end users according to their preferences. Therefore, we want to answer the following research question:

How do consumer choices in regards to delivery options of online purchased groceries affect the sustainability of last mile logistics?

In order to answer the research question, different delivery scenarios are developed and evaluated with regard to their sustainable impact.

The remainder of the paper is as follows. After having presented the motivation of this research and the research question, Sect. 2 shows theoretical notions on online grocery retailing, last mile logistics and its delivery options, as well as last mile related modeling is presented. Section 3 includes an explanation of the methodology of simulation modeling anda description of the processes. This is followed by the presentation and discussion of the identified results in Sect. 4. The paper ends in Sect. 5 with a conclusion, limitations, and an outlook for further research. 


\section{Theoretical Background}

\subsection{Online Grocery Retailing and Its Logistics Challenges}

With an annual growth of around 60\% between 2019 and 2020, the increase of online grocery retailing was significantly higher than the entire retail sector in the online business (HDE Online-Monitor 2021). Despite this significant growth rate, the market share of online grocery retailing is still relatively low, as only two percent of all grocery items are purchased online (HDE Online-Monitor 2021).

This is due to the many obstacles that make online grocery retailing more difficult than stationary retailing. These include issues of missing quality checks of purchased products during the purchasing process or the challenges of delivering fresh or frozen goods that trigger concerns among consumers (Deges and Speckmann 2020). In addition, the overall competition is considered to be extremely high due to a very good local supply situation through stationary retailing, the habitual structures of consumers, low margins and a high price sensitivity of consumers, who are often not willing to pay additional delivery costs (Heinemann 2020).

The supply chains for groceries differ significantly when stationary retailing is compared with online retailing. In conventional supply chains of stationary retailing, goods are delivered from manufacturers to the central distribution centers of retailers, from where they are forwarded to the local stores. In online supply chains, these process steps between manufacturer and end consumers can be reduced (Ehrler et al. 2019). End users buy and receive their goods either directly from the producer, similar to traditional market stalls, or from wholesalers or retail distribution centers (Seidel et al. 2016). In stationary retailing, ultimate logistics operations such as picking, packing, and delivery of individual orders are handled by consumers themselves, whereas in online grocery retailing, these fulfillment operations are transferred back to retailers and/or manufacturers (Yumurtacı Hüseyinoğlu et al. 2020; Kämäräinen and Punakivi 2002).

Furthermore, many logistics processes in the grocery retailing sector are subject to special legal regulations and controls in the areas of food hygiene, temperature safety, data protection and product traceability (Dworak and Burdick 2002; Vahrenkamp et al. 2012; Arnold et al. 2008). For example, legal requirements stipulate that the end consumer must be guaranteed that groceries remain fresh until the best-before date (Hagenmeyer 2006). This is particularly relevant for fresh products such as meat and sausage products as well as fruit and vegetables (Vahrenkamp et al. 2012). Consequently, an uninterrupted cold chain between producers and consumers is essential. 


\subsection{Modeling Last Mile Logistics and Its Delivery Options}

\subsubsection{Last Mile Definition and Delivery Options}

The last mile is this part of a supply chain in which an order is delivered from the last distribution center, collection point or local warehouse to its destination (Umundum 2020). The final destination can be a private end user or a company (Clausen et al. 2016). Various players, such as manufacturers, retailers, and logistics service providers, are involved in managing the last mile. The player with the highest bundling potential can manage the last mile most efficiently and cost-effectively; today, this is most likely to be logistics service providers (Brabänder 2020).

The last mile offers a variety of delivery options, which differ significantly in terms of sustainability impact and at the same time offer the possibility of considering consumer-specific delivery choices. This includes the question of which means of transport is used to cover the last mile. This can be done, for example, by conventional vehicles with combustion engines or electrically powered vehicles such as e-cars or e-bikes. Cargo bikes are also becoming increasingly important, especially in hard-to-reach areas in city centers (Saenz et al. 2016). Furthermore, there are many design options in terms of speed of delivery. Consumers demand short delivery times in particular so that same-day or next-day delivery is becoming increasingly popular in online retailing (Winkenbach and Janjevic 2018). These requirements pose major problems for logistics service providers, as short delivery times lead to rising costs, make route planning more complicated, reduce vehicle utilization, and increase $\mathrm{CO}_{2}$ emissions per package (Witten and Schmidt 2019). Also, different time slots for delivery can be offered to match individual consumer preferences. The selection of a time of the day is intended to ensure that the consumer is present at the time of delivery (Agatz et al. 2008). So far, the choice for a specific delivery time is limited, and the times for delivery specified by logistic service providers often collide with consumers' work schedules (Grant et al. 2014). Since successful first-time delivery has a strong influence on a sustainable delivery, there is great potential for logistics service providers to adapt their delivery times to the preferences of consumers.

Finally, different delivery locations can be adjusted to consumer preferences and have significantly different effects on $\mathrm{CO}_{2}$ emissions during delivery. Consumers clearly prefer home delivery, which is the most common delivery option. The problem here, however, is that consumers often are often not present at the time of delivery, which triggers further delivery attempts and additional trips. There are concepts to avoid this problem and enable more sustainable delivery, such as click-and-collect, which involve self-collection by the consumer from the store or a packing station (Mangiaracina et al. 2019; Schnedlitz et al. 2013). 


\subsubsection{Modeling the Last Mile}

Modeling last mile logistics often focuses on finding better algorithms for scheduling and clocking delivery trips for a wide variety of scenarios. It is considered as a special sort of a Vehicle Routing Problem (VRP), as last mile deliveries are usually constrained by capacity limits imposed by the vehicles and given time windows. Consequently, it is often referred to as a (Capacitated) Vehicle Routing Problem with Time Windows (VRPTW). Thereby, the focus is often on the reduction of vehicles. However, Ombuki et al. (2006) developed multi-objective genetic algorithms, where the number of vehicles and the incurred costs is equally important.

Depending on the application, almost any number of constraints can be added to the basic VRP model. For example, Shen et al. (2018) included the evolution of $\mathrm{CO}_{2}$ emissions costs for a system with multiple depots and time windows (MDOVRPTW). They showed that adapting the delivery strategy to emissions regulations (costs and quotas) decreases overall costs. Current research also investigates the use of electric vehicles, where Caggiani et al. (2021) extend the VRPTW by including aspects of staggered delivery and the need to (partially) charge vehicles (2E-EVRPTW-PR). They conclude that despite these additional constraints, zeroemission strategies for the last mile can be worthwhile.

Also consumer accessibility impacts last mile transportation costs, which Özarık et al. (2021) have investigated by incorporating information on whether consumers are accessible into route planning and show that this can reduce overall costs.

Another important parameter that needs to be incorporated in a modeling approach refers to the problem that the adaptation of logistics processes or conversion of a vehicle fleet to zero-emission drives generates costs that cannot easily be passed on to consumers. Here, Hagen and Scheel-Kopeinig (2021) investigated the acceptance and willingness-to-pay (WTP) of consumers based on a central last mile micro depot (CMD). Their results show that many respondents are interested in using such a last mile service, but only a small proportion is willing to pay more for this additional service with potentially lower emissions.

\section{Developing a Simulation Model for Individualized Sustainable Last Mile Logistics}

\subsection{Modeling Individualized and Sustainable Last Mile Logistics}

Basically, individualization is used to achieve higher consumer loyalty by increasing the individual benefits for the end user (Reichwald et al. 2009). In the manufacturing industry, modularization, and postponement strategies already offer consumers many opportunities for individualization (Kölmel et al. 2019; Shaik et al. 2015). In contrast, the individualization of logistics in the last mile is hardly pronounced. 
In accordance with Gausmann (2009), we understand consumer individuality as the end consumer's ability to make an individual choice from several logistics options. A choice is given if at least two different alternatives are offered to the consumer. With regard to the delivery options of groceries ordered online, such individualization can consist of the end user making a choice from various delivery dates, delivery locations, means of transport or transport packaging.

In our understanding, sustainability in last mile logistics refers primarily to the ecological dimension. Ecological sustainability is given when natural raw materials are only used under consideration of their natural recovery (Reichert et al. 2018). Against this background, we consider all raw materials and the emissions associated with their consumptions that are used and generated during the entire last mile transport process. This includes $\mathrm{CO}_{2}$ emissions during loading, transport, and delivery of groceries ordered online. For example, we are investigating the extent to which $\mathrm{CO}_{2}$ emissions change when different means of transport are used for delivery.

Based on this, we developed a simulation model for the Bremen area to investigate the impact of different logistics options for the delivery of online ordered groceries and their interaction on the respective environmental impact. In contrast to other approaches, the focus is not improving the routing and scheduling algorithm but an investigation of how varying specific logistics options change the outcomes.

Therefore, the model investigates the impact of individual consumers' selected logistics options in terms of dependent KPIs, such as individual $\mathrm{CO}_{2}$ emissions. A model with public average values for consumers' shopping behavior from Germany was parameterized as a reference marker in the first step. We then created a second scenario using actual consumer preferences and shopping behavior from a survey. By comparing these two scenarios, we investigate whether and to what extent individual consumer preferences in the delivery of groceries ordered online have an impact on $\mathrm{CO}_{2}$ emissions and other KPIs.

\subsection{General Process Description}

The simulation represents the following process: Consumers place orders in a continuous process according to their characteristics, which may differ due to the logistics options chosen. The orders received throughout the day are collected. Every time one or more vehicles becomes idle, the simulation tries to schedule all of today's remaining orders and to add as many optional orders (e.g., orders that could be delivered over the next five days). The applied routing tries to ensure that both the consumers' wishes can be fulfilled while obtaining a high vehicle utilization. In this first step, two vehicles with different engine types are available; in the further course, fleets with only one engine type are considered. In all cases, each route starts and ends at the main depot. Figure 1 illustrates this process in a schematic way.

The simulation collects KPIs, such as the total weight, the number of consumers or the distance driven per tour for each tour and individual order. The simulation 


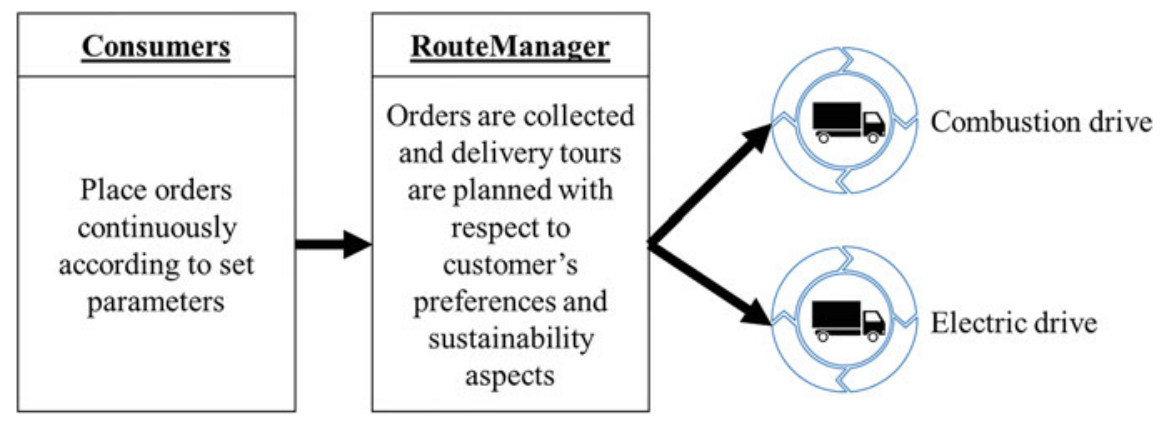

Fig. 1 Process model from ordering to delivery

calculates the individual environmental impact of consumer-related emissions using these KPIs. A detailed description of this approach is given in the following sections.

\subsection{Simulation Model Description}

Our simulation model was created with the AnyLogic software that uses Java as the programming language and provides an internal OpenStreetMaps GIS Map for routing and visualization. As the routing problem, a Capacitated VRP with Time Windows (CVRPTW) was identified, the GraphHopper's jsprit Libraries and a precalculated distance matrix were used to solve it. For each scenario in every variation, five runs over a simulation time of 30 days were done.

The core elements of the simulation model include agents for consumers and vehicles, in which the ordering and delivery behavior are described, and agents who manage incoming orders and optimize the routes. All these elements are presented below.

\subsubsection{Consumers and Transport Matrix}

The simulation model uses a consumer matrix consisting of 200 consumers randomly distributed in Bremen city. The corresponding distance matrix was calculated a priori using street distances within a GIS map. The resulting transport network uses the OpenStreetMap function in AnyLogic to drive along real roads and not just weighted edges in an artificial network.

For our simulation, we include the following delivery options and their attributes:

Each consumer is assigned to one of the possible values for each attribute. The distribution among the different values is based on consumer-specific preferences from our primary and secondary data sources. These logistics options determine different consumer-specific values that are essential for the simulation. For example, 


\begin{tabular}{l|l}
\hline- Number of persons & $(1,2,3,4,5)$ \\
\hline- Order frequency & (once a week, twice a week) \\
\hline - Deposit & (yes, no $)$ \\
\hline - Desired time slots & $(07-14 \mathrm{~h}, 14-20 \mathrm{~h}, 07-20 \mathrm{~h})$ \\
\hline - Desired transport vehicle & (combustion, electric) \\
\hline- Desired period & (same day, next day, within next five days) \\
\hline
\end{tabular}

the number of people, the order frequency, and the desire for storage (impersonal delivery) determine each order's weight and the respective time required for packing and unloading. Traffic volumes differ throughout the day. Therefore, if a desired time slot with higher traffic volume is chosen, deliveries take longer and fuel consumption increases due to more stop-and-go sequences.

\subsubsection{Vehicles}

Our system consists of two delivery vehicles. Depending on the scenario, there are two combustion vehicles, two electric or one each. These two types mainly differ in consumption-related emissions and reactions to different traffic events. The specific total consumption con total, given in Eq. (1) is determined by the type of engine and its related base consumption con base as well as by a load weight factor con $_{\text {weight }}$ and a traffic influencing factor con $_{\text {traffic }}$ that reflects, e.g., different speeds and frequent stops depending on the time of day.

$$
\operatorname{con}_{\text {total }}=\operatorname{con}_{\text {base }} \cdot\left(\operatorname{con}_{\text {weight }}+\operatorname{con}_{\text {traffic }}\right)
$$

Equation (1) considers that the proportion per individual load is higher with a small total load and shrinks with the increasing total load. Thus, the respective consumption (diesel or electricity) is calculated for each order and can be offset against the respective specific emission values. Combustion vehicles tend to have higher fuel consumption according to higher amounts of stop-and-go-frequencies, resulting in a lower average speed (Olivera et al. 2015).

\subsubsection{Routing}

For the simulation, a dynamic planning problem has to be solved since new orders can also arrive during a day, which in the most extreme case are intended to be executed for the current day and should accordingly also be scheduled for the day if possible. Therefore, the agent first generates a route for orders that need to be completed on the same day. Afterward, the agent incrementally adds orders that might be scheduled for today but also could be delivered the following days. This process ensures a high vehicle utilization and tries to keep the number of orders on consecutive days low. The agent selects these additional orders depending on their 
urgency, i.e., it first tries to add orders that would be due the next day, then the day after and so on. The agent terminates the planning when the resulting route would not cover all orders anymore and assigns the complete plan to the idle vehicles.

\subsubsection{Calculating Consumer-Related Emissions}

The distance, the respective speed, the general traffic situation, the transport weight and the vehicle's capacity utilization result in the corresponding consumption (in this case, diesel or electricity) and therefore determine the total $\mathrm{CO}_{2}$ emissions. By multiplication with the respective specific emission factor, a total value with the unit $\mathrm{kg} \mathrm{CO}$ eq. per tour can be determined.

To get a reasonable emission share for each order, neither the consumer-related transport weight share nor the driven distance are suitable as sole calculation factors. Since a fully-loaded vehicle has a higher consumption than an empty one, the consumer's position within the planned tour influences the resulting emissions. To take into account that consumers have no active influence on their position, an allocation method is chosen that puts the product of distance and delivery weight per order in relation to the sum of all orders per tour shown in Eq. (2). Therefore, values per consumer and the total sum are rather determined by the consumers' choice of logistic options than by the tour-planning algorithm setting the sequence.

$$
\text { prop }_{\text {order }}=\frac{\text { distance }_{\text {order }} \cdot \text { delivery weight }_{\text {order }}}{\text { distance }_{\text {tour }} \cdot \text { delivery weight }_{\text {tour }}}
$$

Using this method, orders with very little weight but long distances and orders with significant weight but short distances get their fair share of the total. Having calculated the individual proportion of the respected tour, the amount of emissions for each consumer in the unit $\mathrm{kg} \mathrm{CO}_{2}$ eq. can be determined by applying the formula shown in Eq. (3):

$$
\text { emission }_{\text {order }}=\text { prop }_{\text {order }} \cdot \text { emission }_{\text {totalTour }}
$$

\section{Results and Discussion}

\subsection{Experimental Design}

As mentioned before, the focus lies on creating data on consumer-related choices of logistics options. Therefore, in the different scenarios, varying choice sets are adjusted, and the resulting data is analyzed.

Table 1 shows the consumer-related features, their corresponding option lists and the assigned distributions. For the baseline scenario, literature values were used for the two features number of person groceries are ordered for and order frequency 
Table 1 Features and distributions for the baseline and the empirical numbers scenario

\begin{tabular}{l|l|l|l}
\hline & & \multicolumn{2}{|l}{ Assigned distributions in \% } \\
\cline { 3 - 4 } Feature & Option list & $\begin{array}{l}\text { Baseline } \\
\text { scenario }\end{array}$ & $\begin{array}{l}\text { Scenario with } \\
\text { empirical numbers }\end{array}$ \\
\hline $\begin{array}{l}\text { Number of person } \\
\text { groceries are ordered for }\end{array}$ & $(1,2,3,4,5)$ & $(50,31,9,7,3)^{\mathrm{a}}$ & $(35,40,13,6,6)$ \\
\hline $\begin{array}{l}\text { Order frequency per } \\
\text { week }\end{array}$ & (once, twice, daily) & $(69,27,4)^{\mathrm{b}}$ & $(42,54,4)$ \\
\hline Deposit & (yes, no) & $(20,80)$ & $(20,80)$ \\
\hline Desired time slot & $\begin{array}{l}(07-22 \mathrm{~h}, 08-14 \mathrm{~h}, \\
14-20 \mathrm{~h})\end{array}$ & $(20,20,60)$ & $(20,20,60)$ \\
\hline Desired transport & (Diesel, electric) & $(50,50)$ & $(50,50)$ \\
\hline Desired period & $\begin{array}{l}\text { (SameDay, NextDay, } \\
\text { within 5 days) }\end{array}$ & $(20,50,30)$ & $(20,50,30)$ \\
\hline
\end{tabular}

${ }^{a}$ In accordance with State Statistical Office Bremen (2016)

${ }^{\mathrm{b}}$ In accordance with Kläver et al. (2020)

per week according to the sources given. A total of 260 participants took part in our survey on grocery shopping behavior, from which the distributions shown for the two features are derived. The remaining distributions are based on assumptions made by the authors.

By comparing the results of our survey data with the data used for the baseline scenario, three interesting aspects appear:

1. There is a shift in how many people are assigned to one grocery purchase.

2. The number of shopping trips per week differs significantly.

3. The vast majority of grocery shopping trips is done by car.

Whereas the data from the State Statistical Office Bremen say that almost 50\% of all orders are for one person, only $35 \%$ of the survey participants chose this answer. The most noticeable part of this shift can be found in the shopping for two people, from $31 \%$ in the baseline scenario to $40 \%$ in the empirical scenario. Only small changes can be seen in the numbers for more than two people.

The second significant difference relates to the number of shopping trips per week. Survey data from Kläver et al. (2020) state that almost $70 \%$ of all consumers do grocery shopping once, or even less, a week. In our survey, this value drops to only $42 \%$, but at the same time, the number for doing grocery shopping twice a week doubles to $54 \%$. In both cases, daily shopping is only done by $4 \%$ of the participants. Lastly, our survey shows that grocery purchases are made almost exclusively in stationary stores and that about $70 \%$ of the survey participants use their car for this purpose. Here, the question arises whether $\mathrm{CO}_{2}$ emissions can be reduced if online orders are placed and delivered by a small number of vehicles instead of many consumers do shopping trips by car.

Using the two different data sets, conclusions can be drawn about how the changing consumer preferences affect the delivery system. However, at the same time, in order to investigate developments when different vehicle fleets are available, 
simulations of these fleets were changed in a third step. While both vehicle types are selected at $50 \%$ in the initial scenarios, $100 \%$ use of one vehicle type was simulated for comparison purposes.

\subsection{Experimental Results}

In Table 2, the average results of five simulation run for each scenario are presented, beginning with the mixed vehicle fleet, followed by the combustion drive only and the electric drive only scenario. Finally, in Fig. 2, a comparison of all scenarios based on the emissions per order is shown.

The results show that consumer preferences have a direct impact on the logistics system. However, as illustrated in Fig. 2, within each vehicle distribution scenario, the average emissions per order remain similar at around $4.3,3$, and $1.3 \mathrm{~kg} \mathrm{CO}_{2} \mathrm{eq}$. despite the change in consumer behavior, that leads to an apparent increase of around $15 \%$ of orders for all vehicle distributions. Figure 2 also shows that the average results on the emissions per order are always at the same level, but the variances are clearly different. Since the combustion only fleets show greater

Table 2 Average results of five simulation runs for a mixed vehicle fleet, combustion vehicles and electric vehicles only

\begin{tabular}{|c|c|c|}
\hline KPI & Baseline scenario & Scenario with empirical numbers \\
\hline \multicolumn{3}{|c|}{ Average results of five simulation runs for a mixed vehicle fleet } \\
\hline Emissions per order $/ \mathrm{kg} \mathrm{CO}$ eq. & 3.09 & 3.05 \\
\hline Orders delivered & 707.00 & 833.60 \\
\hline Tours done & 99.60 & 99.00 \\
\hline Orders per tour & 7.18 & 8.45 \\
\hline Delivery weight per tour $/ \mathrm{kg}$ & 101.56 & 157.62 \\
\hline Distance per order $/ \mathrm{km}$ & 14.31 & 14.34 \\
\hline \multicolumn{3}{|c|}{ Average results of five simulation runs for combustion vehicles only } \\
\hline Emissions per order $/ \mathrm{kg} \mathrm{CO}$ eq. & 4.36 & 4.24 \\
\hline Orders delivered & 762.60 & 856.20 \\
\hline Tours done & 105.00 & 99.20 \\
\hline Orders per tour & 7.35 & 8.69 \\
\hline Delivery weight per tour $/ \mathrm{kg}$ & 119.95 & 147.97 \\
\hline Distance per order $/ \mathrm{km}$ & 13.42 & 13.06 \\
\hline \multicolumn{3}{|c|}{ Average results of five simulation runs for electric vehicles only } \\
\hline Emissions per order $/ \mathrm{kg} \mathrm{CO} 2$ eq. & 1.35 & 1.30 \\
\hline Orders delivered & 705.20 & 833.20 \\
\hline Tours done & 105.20 & 101.20 \\
\hline Orders per tour & 6.76 & 8.29 \\
\hline Delivery weight per tour $/ \mathrm{kg}$ & 91.14 & 140.54 \\
\hline Distance per order $/ \mathrm{km}$ & 13.63 & 13.04 \\
\hline
\end{tabular}




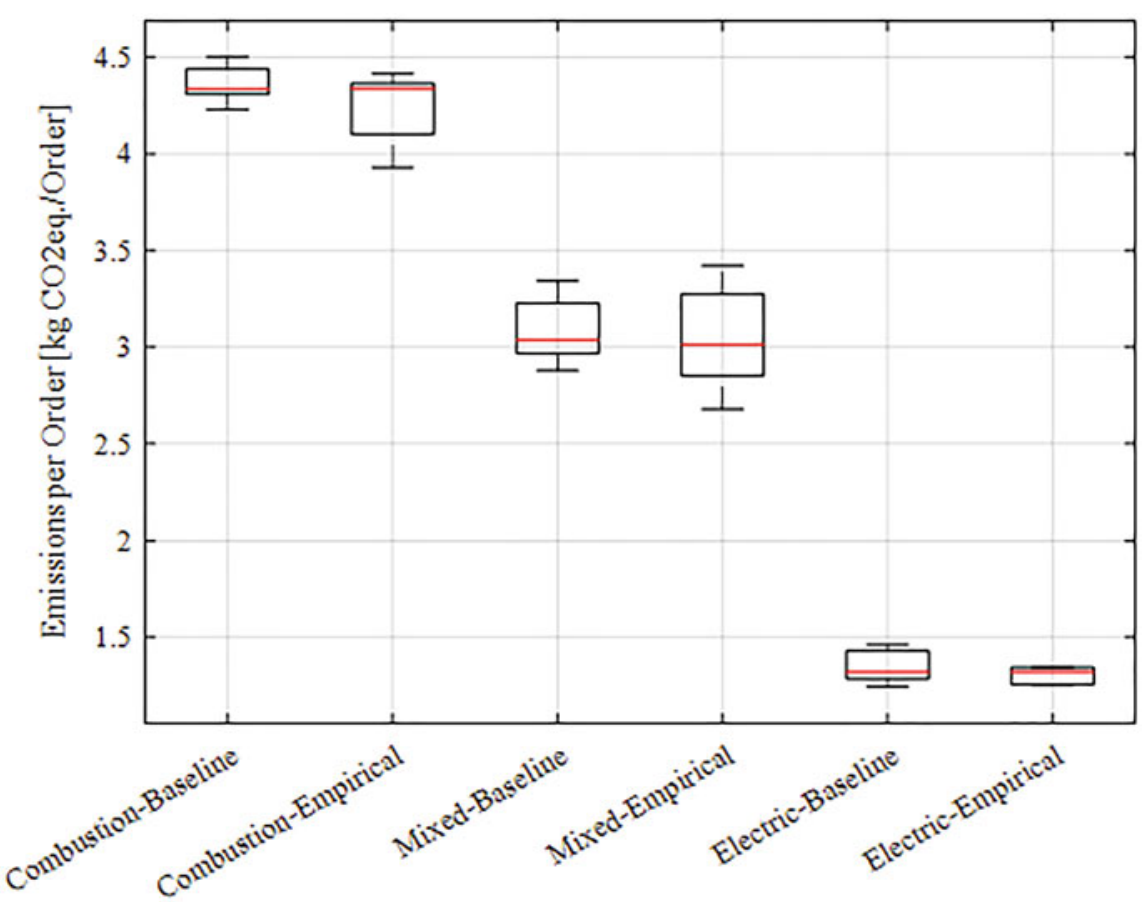

Fig. 2 Visualization of emissions per order for different vehicle distribution

fluctuations and higher values, these vehicles mainly shape the results for the mixed fleets.

Although more orders had to be delivered, the total amount of tours needed shrinks at least by a small factor. This development is also accompanied by an increase in delivery weight per tour. For both the mixed and the electric-only fleet, rises of more than $50 \%$ can be seen. However, for all vehicle distributions, it becomes obvious that there is a low utilization. Based on a maximum load capacity of around $1000 \mathrm{~kg}$, the utilization in all baseline scenarios is around $10 \%$. In comparison, in the empirical scenarios, it is still around almost $15 \%$. Contrary to the weight per tour, for distances per tour, only small changes can be seen.

Finally, for all vehicle distributions, more efficient tours reduce emissions per order, which is achieved through the change in consumer behavior. Considering the assumptions made for this simulation model, full electrical fleets cause the smallest amount of emissions, but even a mixed fleet can significantly reduce environmental impacts. 


\subsection{Discussion on Results}

The KPI weight per trip shows how consumer behavior impacts the environmental compatibility of the transport of online ordered groceries. Having the possibility to choose between several options, individualized deliveries are generated for consumers, but the providers of last mile logistics depend on a critical amount of consumers with similar selections made to generate environmentally friendly delivery tours. Although the planning algorithm tries to bundle as many orders as possible, our approach clearly shows the limits for optimizing a consolidation of the orders made by 125 active consumers with two vehicles only.

Since a majority of the respondents in our survey stated that purchases are made by car, it is worth estimating the emissions if all orders were picked up from stationary retail outlets by car. According to Schewelsky et al. (2020), $\mathrm{CO}_{2}$ emissions per shopping trip in Germany amount to around $1.28 \mathrm{~kg} \mathrm{CO}_{2}$ eq. In our simulation, comparable values result when delivery is made in electric vehicles only (1.35 kg CO 2 eq. for the baseline scenario and $1.3 \mathrm{~kg} \mathrm{CO}_{2}$ eq. for the scenario with empirical numbers). This highlights the potential positive sustainability impacts of using electric-powered vehicles to deliver groceries ordered online. In addition, traffic would be relieved if only two delivery vehicles were in use compared to everyone doing their grocery shopping by car. In contrast, the emissions in our simulation are more than twice as high when delivered with combustion vehicles. In this case, a shopping trip by car is less harmful to the environment than supplying the urban area from a single location that is positioned for practical reasons in the vicinity of the grocery store. In addition to the already mentioned low utilization of the delivery vehicles, a look at the distances per order also shows why the emission values are comparatively high. While in the simulation scenarios, distances of around $14 \mathrm{~km}$ per order have to be driven, the figure for private car trips is only around $5 \mathrm{~km}$ (Schewelsky et al. 2020). However, the results of our simulation do not allow a generally valid statement about how the emissions from shipping groceries ordered online behave compared to shopping trips by private car. Instead, it shows the need to investigate under which circumstances a breakeven is achieved, taking into account consumer behavior, fleet size, drive types, and possibly the number of locations concerning delivery areas and traffic situations and their interaction.

The fact that vehicle utilization has a significant impact on the efficiency and the outcomes of delivery routes is not new. However, this first simulation study shows that the delivery options directly influence the whole last mile logistics system. Therefore, to achieve a compromise between fulfilling consumers' wishes and planning and scheduling delivery routes with an environmental impact as little as possible, there is a need for a dynamic planning process. According to Özarık et al. (2021), who included data about the presence of consumers in their planning and scheduling system, information about all orders with specific restrictions like a particular time window or a delivery area could be considered. In that way, with every new order coming in, there would be a continuous calculation of transport utilization and costs. From this, different options can be derived and presented 
to the consumer, who then has the opportunity to decide whether to accept a more environmentally friendly option or prefer to have their original delivery requirements fully met.

\section{Conclusions, Limitations, and Outlook}

The purpose of this paper was to show how consumer choices in regards to delivery options of online purchased groceries affect the sustainability of last mile logistics. Therefore, we developed a simulation model and analyzed two different scenarios. By adapting the baseline scenario to individual consumer preferences, the number of orders is increased, but at the same time, the number of tours is reduced, resulting in a slightly better utilization of vehicle capacity. Even if these improvements are only marginal, the integration of consumer preferences for the delivery of groceries ordered online can be expected to improve rather than worsen the sustainability effects of deliveries. Our results also show that electrically powered vehicles have a decisive influence on the sustainability of delivery. For example, the emissions in the scenario with individual consumer preferences and the exclusive use of electric vehicles are $1.3 \mathrm{~kg} \mathrm{CO}_{2} \mathrm{eq}$, while this value is $4.24 \mathrm{~kg} \mathrm{CO}_{2} \mathrm{eq}$ for the exclusive use of combustion vehicles. Our findings further indicate that vehicle utilization is low in both scenarios. In the baseline scenario, vehicle utilization is around $10 \%$, and in the scenario with empirical data, it is around $15 \%$. Since vehicle utilization is another critical factor in assessing sustainability, there is still significant potential here to make the delivery of groceries ordered online more environmentally friendly.

Even though the costs are a critical factor in the design of the last mile, we have not yet addressed this aspect. This is because the focus of this study is on sustainable and individualized delivery options, and costs, in the long run, will be integrated into our approach as a result of a selected delivery option. For future research, it is, therefore, necessary to assign a possible price to the individual delivery options. Since the delivery options will differ depending on the selection of a delivery option, a dynamic pricing model would be appropriate. As individual adjustments to delivery lead to additional costs for logistics service providers or retailers, the extent to which consumers are willing to contribute to the delivery costs incurred must further be investigated (Witten and Schmidt 2019). We expect that the willingnessto-pay a surcharge for delivery will be higher if the chosen delivery options have a positive impact on sustainability.

For this study, only three features for describing consumer behavior on last mile logistics options were investigated. Nevertheless, it can be seen that there is a direct link between chosen logistics options and responding emissions. Therefore, in future work, sensitive analysis on all the other features needs to be done to investigate the interaction of all features in different circumstances. In the long term, the simulations presented can be integrated into the online ordering process of groceries. After a consumer selects a delivery option for the groceries ordered online, the consumer would get direct feedback on the sustainable impact of that 
delivery option. This allows consumers to reflect and evaluate their decision. If desired, the consumer can then adjust his decision and tailor the last mile logistics to the individual and sustainable preferences (Freitag and Kotzab 2020).

\section{References}

Agatz, N., Campbell, A.M., Fleischmann, M., Savels, M.: Challenges and opportunities in attended home delivery. In: Golden, B., Raghavan, S., Wasil, E. (eds.) The Vehicle Routing Problem: Latest Advances and New Challenges, vol. 43, pp. 379-396. Springer, Boston, MA (2008)

Arnold, D., Isermann, H., Kuhn, A., Tempelmeier, H., Furmans, K. (Eds.), Handbuch Logistik, VDI-Buch. Springer Berlin Heidelberg, Berlin, Heidelberg. (2008). https://doi.org/10.1007/ 978-3-540-72929-7

Brabänder, C.: Die Letzte Meile: Definition, Prozess, Kostenrechnung und Gestaltungsfelder (2020). Available at: https://doi.org/10.1007/978-3-658-29927-9 (accessed 29 June 2020)

Caggiani, L., Colovic, A., Prencipe, L.P., Ottomanelli, M.: A green logistics solution for last-mile deliveries considering e-vans and e-cargo bikes. Transportation Research Procedia. 52, 75-82 (2021)

Clausen, U., Stütz, S., Bernsmann, A., Heinrichmeyer, H.: Die Letzte Meile. ZF-Zukunftsstudie 2016. Fraunhofer IML, Stuttgart, pp. 1-34 (2016)

Deges, F., Speckmann, A.-S.: Lieferservice Im Online-Lebensmittelhandel: Analyse Des Spannungsfeldes Zwischen Den Erwartungen Der Konsumenten Und Den Leistungsversprechen Der Anbieter, Diskussionsbeitrag No. 19, Europäische Fachhochschule Brühl, Brühl (2020)

Dworak, T., Burdick, B.: Ökologische Und Soziale Chancen Und Risiken Des E-Commerce Im Nahrungsmittelsektor. Wuppertal Papers No. 126, Wuppertal Institut für Klima, Umwelt, Energie, Wuppertal (2002). Available at: http://nbn-resolving.de/urn:nbn:de:bsz:wup4-opus15186

Ehrler, V.C., Schöder, D., Seidel, S.: Challenges and perspectives for the use of electric vehicles for last mile logistics of grocery e-commerce - Findings from case studies in Germany. Res. Transp. Econ. p. 100757 (2019)

Freitag, M., Kotzab, H.: A concept for a consumer-centered sustainable last mile logistics. In: Freitag, M., Haasis, H.-D., Kotzab, H., Pannek, J. (eds.) Dynamics in Logistics, pp. 196-203. Springer, Cham (2020)

Gausmann, O.: Kundenindividuelle Wertschöpfungsnetze, 1. Aufl., Gabler, Wiesbaden (2009). https://doi.org/10.1007/978-3-8349-9917-7

Gevaers, R., Van de Voorde, E., Vanelslander, T.: Characteristics and typology of last mile logistics from an innovation perspective in an urban context. In: Macharis, C., Melo, S. (eds.) City Distribution and Urban Freight Transport: Multiple Perspectives, pp. 56-74. Edward Elgar, Cheltenham (2011)

Grant, D.B., Fernie, J., Schulz, B.: Enablers and barriers in german online food retailing. Suppl Chain Forum Int J. 15(3), 4-11 (2014)

Hagen, T., Scheel-Kopeinig, S.: Would customers be willing to use an alternative (chargeable) delivery concept for the last mile? Working Papers, No. 17. Res. Transp. Bus. Manag. p. 100626 (2021)

Hagenmeyer, M.: Lebensmittel-Kennzeichnungsverordnung: mit Los-KennzeichnungsVerordnung und Fertigpackungsverordnung (Auszug); Kommentar, 2. Aufl., Beck, München (2006)

HDE Online-Monitor:: Handelsverband Deutschalnd, IFH Köln, pp. 1-59 (2021)

Heinemann, G.: Der neue. Online-Handel: Geschäftsmodelle, Geschäftssysteme und Benchmarks im E-Commerce. Springer, Wiesbaden (2020). https://doi.org/10.1007/978-3-658-28204-2 
Kläver, K., Profeta, A., Kircher, C. (2020): Kauf-Und Ernährungsverhalten Der Deutschen Verbraucher Vor Und Während Der Covid-19-Pandemie: Tabellen-Und Grafikband, Landesinitiative Ernährungswirtschaft Niedersachsen und Deutes Institut für Lebensmitteltechnik e.V. Available at: https://www.dil-ev.de/fileadmin/user_upload/Covid_19_Studie_1_.pdf

Kölmel, B., Pfefferle, T., Bulander, R.: Mega-Trend Individualisierung: Personalisierte Produkte und Dienstleistungen am Beispiel der Verpackungsbranche. In: Deutscher Dialogmarketing Verband e (Ed.), Dialogmarketing Perspektiven 2018/2019, Springer, Wiesbaden, pp. 243-260 (2019)

Kämäräinen, V., Punakivi, M. (2002). Developing cost-effective operations for the e-grocery supply chain. International Journal of Logistics: Research and Applications, 5(3), 285-298.

Mangiaracina, R., Perego, A., Seghezzi, A., Tumino, A.: Innovative solutions to increase last-mile delivery efficiency in B2C e-commerce: a literature review. International Journal of Physical Distribution \& Logistics Management. 49(9), 901-920 (2019)

Olivera, A.C., García-Nieto, J.M., Alba, E.: Reducing vehicle emissions and fuel consumption in the city by using particle swarm optimization. Appl. Intell. 42(3), 389-405 (2015)

Ombuki, B., Ross, B.J., Hanshar, F.: Multi-objective genetic algorithms for vehicle routing problem with time windows. Appl. Intell. 24(1), 17-30 (2006)

Özarı, S.S., Veelenturf, L.P., van Woensel, T., Laporte, G.: Optimizing e-commerce last-mile vehicle routing and scheduling under uncertain customer presence. Trans. Res. Part E Logist. Transp. Rev. 148, 102263 (2021)

Pronello, C., Camusso, C., Valentina, R.: Last mile freight distribution and transport operators' needs: Which targets and challenges? Transp. Res. Proc. 25, 888-899 (2017)

Reichert, D., Cito, C., Barjasic, I.: Ressourceneffizienz und Nachhaltigkeit. In: Lean \& Green: Best Practice, pp. 5-23. Springer, Wiesbaden (2018)

Reichwald, R., Piller, F., Ihl, C.: Interaktive Wertschöpfung: Open Innovation, Individualisierung und neue Formen der Arbeitsteilung. Gabler, Wiesbaden (2009)

Saenz, J., Figliozzi, M., Faulin, J.: Assessment of the Carbon Footprint Reductions of Tricycle Logistics Services. Transp. Res. Record J. Transp. Res. Board. 2570(1), 48-56 (2016)

Savelsbergh, M., Van Woensel, T.: 50th Anniversary Invited Article-City Logistics: Challenges and Opportunities. Transp. Sci. 50(2), 579-590 (2016)

Schewelsky, M., Follmer, R. Dickmann, C.: CO2-Fußabdrücke Im Alltagsverkehr: Datenauswertung Auf Basis Der Studie Mobilität in Deutschland, edited by Umweltbundesamt (2020)

Schnedlitz, P., Lienbacher, E., Waldegg-Lindl, B., Waldegg-Lindl, M.: Last Mile: Die letzten - und teuersten - Meter zum Kunden im B2C ECommerce. In: Crockford, G., Ritschel, F., Schmieder, U.-M. (eds.) Handel in Theorie und Praxis, pp. 249-273. Springer, Wiesbaden (2013)

Seidel, S., Mareï, N., Blanquart, C.: Innovations in e-grocery and Logistics Solutions for Cities. Transp. Res. Proc. 12, 825-835 (2016)

Shaik, A.M., Rao, V.V.S.K., Rao, C.S.: Development of modular manufacturing systems-a review. Int. J. Adv. Manuf. Technol. 76(5-8), 789-802 (2015)

Shen, L., Tao, F. and Wang, S.: Multi-Depot Open Vehicle Routing Problem with Time Windows Based on Carbon Trading. Int. J. Environ. Res. Publ. Health 15(9) (2018). https://doi.org/ 10.3390/ijerph15092025

State Statistical Office Bremen (Ed.). Population and Employment, Households and Families in the State of Bremen 2011 to 2015: Results of the Microcensus with Time Series 2005 to 2015 (2016). Available at: https://www.statistik.bremen.de/sixcms/media.php/13/ AI_AVI_MZ_2011-2015_pdfa.pdf

Ternès, A., Towers, I., Jerusel, M.: Konsumentenverhalten im Zeitalter der Mass Customization: Trends; Individualisierung und Nachhaltigkeit. Springer, Wiesbaden (2015)

Umundum, P.: Die letzte Meile - Königsdisziplin der Logistik. In: Voß, P.H. (ed.) Logistik - die unterschätzte Zukunftsindustrie, pp. 149-162. Springer, Wiesbaden (2020)

Vahrenkamp, R., Kotzab, H., Siepermann, C.: Logistik: Management und Strategien, 7., überarbeitete und erweiterte Auflage. Oldenbourg, München (2012) 
Wegner, K.: Potenziale der Digitalisierung für die letzte Meile in der Logistik. In: Schröder, M., Wegner, K. (eds.) Logistik im Wandel der Zeit - Von der Produktionssteuerung zu vernetzten Supply Chains, pp. 285-301. Springer, Wiesbaden (2019)

Winkenbach, M., Janjevic, M.: Classification of Last-Mile Delivery Models for e-Commerce Distribution: A Global Perspective. In: Taniguchi, E., Thompson, R.G. (eds.) City Logistics 1, pp. 209-229. Wiley, Hoboken, NJ (2018)

Witten, P., Schmidt, C.: Globale Trends und die Konsequenzen für die Logistik der letzten Meile. In: Schröder, M., Wegner, K. (eds.) Logistik im Wandel der Zeit - Von der Produktionssteuerung zu vernetzten Supply Chains, pp. 303-319. Springer, Wiesbaden (2019)

Yumurtacı Hüseyinoğlu, I.Ö., Kotzab, H., Köstepen, K.G., Halaszovich, T.: Assessing consumer logistics functions in grocery shopping: Evidence from an emerging market. J. Mark. Channels. 26(1), 72-86 (2020)

Open Access This chapter is licensed under the terms of the Creative Commons Attribution 4.0 International License (http://creativecommons.org/licenses/by/4.0/), which permits use, sharing, adaptation, distribution and reproduction in any medium or format, as long as you give appropriate credit to the original author(s) and the source, provide a link to the Creative Commons licence and indicate if changes were made.

The images or other third party material in this chapter are included in the chapter's Creative Commons licence, unless indicated otherwise in a credit line to the material. If material is not included in the chapter's Creative Commons licence and your intended use is not permitted by statutory regulation or exceeds the permitted use, you will need to obtain permission directly from the copyright holder. 